Revista Universo Contábil, ISSN 1809-3337

FURB, v. 6, n.4, p.06-20, out./dez., 2010

doi:10.4270/ruc.2010428

Disponível em www.furb.br/universocontabil

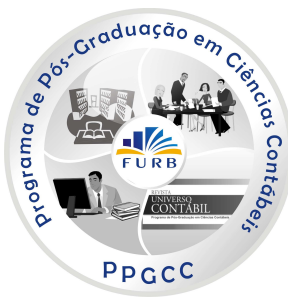

INFLUÊNCIA DO INCENTIVO AO CONSERVADORISMO NAS ESCOLHAS CONTÁBEIS RELACIONADAS AO RECONHECIMENTO DE PROVISÃO DE CONTINGÊNCIAS PASSIVAS*

\title{
INFLUENCE OF CONSERVATISM INCENTIVE IN ACCOUNTING CHOICES RELATED TO THE RECOGNITION OF LIABILITIES CONTINGENCIES PROVISION
}

\author{
César Augusto Tibúrcio Silvai \\ Doutor em Ciências Contábeis pela FEA/USP \\ Professor do Programa Multiinstitucional e Inter-regional de Pós-graduação em Ciências Contábeis \\ UnB/UFPB/UFRN \\ Endereço: Campus Universitário Darcy Ribeiro, Prédio da FACE, $1^{\circ}$ Andar, Salas B1-02, Asa Norte \\ CEP: 70910-900 - Brasília/DF - Brasil \\ E-mail: cesartiburcio@unb.br \\ Telefone: (61) 3307-2345
}

Rodrigo de Souza Gonçalves

Doutorando do Programa Multiinstitucional e Inter-regional de Pós-graduação em Ciências Contábeis

UnB/UFPB/UFRN

Endereço: Campus Universitário Darcy Ribeiro, Prédio da FACE, $1^{\circ}$ Andar, Salas B1-02, Asa Norte

CEP: 70910-900 - Brasília/DF - Brasil

E-mail: rgoncalves@unb.br

Telefone: (61) 3307-2981

Adilson de Lima Tavares

Doutorando do Programa Multiinstitucional e Inter-regional de Pós-graduação em Ciências Contábeis

UnB/UFPB/UFRN

Endereço: Campus Universitário da UFRN - Lagoa Nova

CEP: 59072-970 - Natal/RN - Brasil

E-mail: adilson.tavares@uol.com.br

Telefone: (84) 3215-3486

Diana Vaz de Lima

Doutorando do Programa Multiinstitucional e Inter-regional de Pós-graduação em Ciências Contábeis

UnB/UFPB/UFRN

Endereço: Campus Universitário Darcy Ribeiro, Prédio da FACE, $1^{\circ}$ Andar, Salas B1-02, Asa Norte

CEP: 70910-900 - Brasília/DF - Brasil

E-mail: diana_lima@unb.br

Telefone: (61) 3307-2981

\footnotetext{
Artigo recebido em 27.07.2009. Revisado por pares em 14.09.2009. Reformulado em 14.10.2009. Recomendado para publicação em 21.10.2009 por Ilse Maria Beuren (Editora). Publicado em 30.11.2010. Organização responsável pelo periódico: FURB.
} 


\section{RESUMO}

Este estudo investiga as escolhas contábeis relacionadas ao reconhecimento de provisão de contingências passivas em situações de seleção adversa. A seleção adversa surge no momento pré-contratual (AKERLOF, 1970), onde ocorre a assimetria informacional entre principal e agente (JENSEN, 2003). Utilizando os assuntos tratados na Deliberação CVM n 489/2005, os autores procuram discutir se os contadores conseguem, em situações reais, não ser influenciados pelo ambiente em que estão inseridos. Para tanto, é realizado um experimento (LIBBY, BLOOMFIELD e NELSON, 2002; SPINKLE, 2003) com 343 estudantes de graduação e pós-graduação em Ciências Contábeis, divididos em dois grupos, sendo o ambiente em um deles alterado pelo uso do chamariz (ARIELY, 2008). Os cenários foram controlados por idade, gênero, nível de experiência, escolaridade e grau de certeza, e os resultados revelam perfil menos conservador para os homens, os inexperientes e os mais jovens, com variações entre duvidosos e confiantes. Por sua vez, as mulheres mais experientes foram conservadoras em todas as proposições do experimento, não sofrendo influência do chamariz. Com os indivíduos que apresentaram perfis extremos (mais, ou menos, conservadores), os resultados são relevantes para os seniores e homens, ratificando as análises precedentes de que a influência do chamariz ocorreu, efetivamente, para os homens. Verificase, portanto, que a presença do chamariz pode afetar as decisões, e que a influência pode variar conforme o perfil do indivíduo, tendo os homens um perfil mais agressivo e com maior propensão ao gerenciamento de resultados.

Palavras-chave: Seleção adversa. Decisão em contabilidade. Gerenciamento de resultados. Provisão de contingências passivas. Pesquisa experimental.

\section{ABSTRACT}

This research examines the accounting choices related to the recognition of contingencies provision in situations of adverse selection. The adverse selection occurs at the precontractual moment (AKERLOF, 1970), when there is an informational asymmetry between main and agent (JENSEN, 2003). By using the subjects addressed in the CVM Deliberation 489/2005, the authors try to discuss whether accountants manage or not, in real situations, not to be influenced by the surrounding in which they are. Thus, an experiment is conducted (LIBBY; BLOOMFIELD; NELSON, 2002; SPINKLE, 2003) involving 343 graduation and post-graduation students of Accounting Sciences, divided into two groups, being the surrounding in one of the groups altered by the use of a decoy (ARIELY, 2008). The scenarios were controlled by age, gender, experience level, scholarity and degree of certainty, and the results revealed a less conservative profile among the men, the inexperienced and the younger ones, which varied between doubtful and confident. In the case of the women, the most experienced ones were more conservative regarding all the proposals of the experiment, not suffering any influence from the decoy. Among the individuals who showed extreme profiles (more conservative or less) the results were relevant among the adult men and the senior ones, emphasizing the previous analyses which showed that an effective influence of the decoy occurred in the case of the men. It is verified, therefore, that the presence of a decoy can affect the decisions, and that the influence may vary according to the individual's profile, suggesting that men have a more aggressive profile and are self-directed to results management.

Keywords: Adverse selection. Decision in accounting. Results management. Liabilities contingencies provision. Experimental research. 


\section{INTRODUÇÃO}

Em 2002, a Nobel Foundation premiou Daniel Kahneman e Vernon Smith com o Prêmio Nobel de Economia. Kahneman é um psicólogo israelense, conhecido no campo acadêmico por pesquisas na área comportamental através da prospect theory. Seus estudos mostraram que a racionalidade dos modelos de finanças não é aplicável à realidade do mundo em razão dos erros humanos no processo decisório. Vernon Smith é um economista estadunidense que, ensinando em Purdue, estudou as propriedades dos mercados e seus efeitos sobre o equilíbrio. Anteriormente, Chamberlin, em Harvard, fez pequenos experimentos em sala de aula para ilustrar a falsidade da teoria dos mercados competitivos (GUALA, 2009).

Além de ser uma nova abordagem metodológica para o estudo dos problemas econômicos, a metodologia experimental aplicada a estas situações representa uma tentativa de entender melhor o processo decisório dos chamados agentes econômicos. Em lugar de supor a racionalidade dos agentes e induzir quais seriam as melhores decisões, a metodologia experimental procura reproduzir situações práticas.

Estudos experimentais tendem a reproduzir algumas das condições existentes na realidade do tomador de decisão. Por ser um estudo controlado, é possível reduzir as variáveis de controle e aumentar a amostra. Entretanto, as conclusões podem ser questionadas por não estarem baseadas em dados reais. Ressalta-se que aos primeiros experimentos de Chamberlin, apesar de publicados em 1948 no Journal of Political Economy, não foi atribuída credibilidade cientifica, inclusive pelo próprio autor (GUALA, 2009).

Nos dias de hoje, apesar de ser uma metodologia de pesquisa razoavelmente consolidada na economia, as aplicações práticas na contabilidade ainda são restritas. No Brasil, especificamente, os dois primeiros trabalhos foram desenvolvidos recentemente por Cardoso e Aquino (2009) e Alves e Borba (2009). Cardoso e Aquino (2009) investigaram o problema da classificação das contas do ativo (imobilizado, intangível e estoques) que levam à distorção em razão do seu nível de liquidez. Seus achados indicam que a classificação atualmente utilizada leva a uma assimetria de informações que até o momento é negligenciada pelos auditores e órgãos normatizadores. Já Alves e Borba (2009) usaram uma amostra de 32 estudantes, e analisaram a relevância da informação contábil ambiental para a tomada de decisão em investimento numa empresa. Os participantes consideraram que a informação sobre aspectos ambientais é relevante para decisão numa empresa.

No mesmo sentido de Alves e Borba (2009), a pesquisa aqui apresentada tem por finalidade investigar as escolhas contábeis relacionadas ao reconhecimento de provisão de contingências passivas em situações de seleção adversa. A seleção adversa aparece quando o agente detém informações antes da relação entre agente-principal iniciar (MACHOSTADLER; PÉREZ-CASTRILLO, 2001). O texto utiliza os assuntos tratados na Deliberação CVM n ${ }^{\circ}$ 489/2005: provisões, passivos, contingências passivas e contingências ativas. Usando a metodologia experimental, buscou-se verificar se a presença de um chamariz influencia as decisões contábeis. De forma geral, a neutralidade da contabilidade tem sido destacada na literatura, como se fatores externos não influenciassem a informação produzida.

Em outras palavras, os autores procuraram discutir na pesquisa se os contadores conseguem, em situações reais, não ser influenciados pelo ambiente em que estão inseridos. Isto inclui desde notícias econômicas e políticas até situações pessoais, em que a empresa em que trabalham possui interesse específico em determinados resultados. Neste sentido, a pesquisa realizada também pode ser um interessante ponto de partida para discutir assuntos como isenção do profissional, influência do ambiente, relevância de questões éticas.

O texto está estruturado em cinco partes, além desta introdução. O referencial teórico, com ênfase em seleção adversa e pesquisa experimental, e o proceder metodológico encontram-se a seguir. A discussão sobre a seleção dos participantes e sua influência sobre os 
resultados da pesquisa experimental é realizada antes da análise dos resultados. Finalmente, o artigo é encerrado com as considerações finais.

\section{DA SELEÇÃo ADVERSA À PESQUISA EXPERIMENTAL EM CONTABILIDADE FINANCEIRA}

A assimetria informacional - seja aquela ocorrida entre o principal e o agente, como abordado por Jensen (2003), ou aquela ocorrida entre empresa e participantes do mercado, ou até mesmo em qualquer transação que envolva a necessidade de maiores conhecimentos da contraparte envolvida - tem sido responsável pelo desenvolvimento de uma série de pesquisas ao longo das últimas décadas (AKERLOF, 1970; SPENCE, 1973; WEISS, 1980; STIGLITZ e WEISS, 1981; ABOODY e LEV, 2000; GÂRLEANU e PEDERSEN, 2004; JENSEN, 2003).

A idéia básica dos estudos relacionados à assimetria informacional é a busca por mecanismos, internos ou externos, que minimizem a desvantagem concorrencial gerada pelo descompasso informacional das ações do principal e suas consequiências sobre o bem ora transacionado ou objeto de análise pelo agente.

Em seu artigo seminal, Akerlof (1970) busca identificar os aspectos que envolvem o mercado de carros usados nos Estados Unidos, e menciona que a assimetria informacional é inerente a este processo, já que o vendedor necessariamente possui maiores informações sobre o bem (carros usados) do que o comprador. É justamente neste momento (pré-contratual) que surge a seleção adversa - o comprador (agente) busca obter maiores informações sobre o objeto ora transacionado, com o fito de analisar se o valor atribuído pelo vendedor (principal) é justo sob as condições oferecidas.

Autores como Spence (1973), Weiss (1980), Stiglitz e Weiss (1981) e Puelz e Snow (1994) propõem mecanismos conhecidos como sinalização (signaling) e varredura (screening) para que o agente possa ter melhores condições de negociação e, assim, reduzir a assimetria informacional existente. No âmbito da relação entre empresa e stakeholders, as informações contábeis devem exercer um papel que reduza a assimetria informacional, seja no momento pré-contratual, caracterizado pela seleção adversa, ou pós-contratual, caracterizado pelo risco moral.

Nesse sentido, Libby, Bloomfield e Nelson (2002) comentam a necessidade das pesquisas em contabilidade levarem em consideração variáveis como o comportamento individual no mercado; a melhor robustez no uso dos métodos às questões de pesquisa; o uso da teoria econômica e psicológica e a busca por capturar aspectos relevantes do uso das informações financeiras no processo decisório. Uma das formas de procurar mitigar as fragilidades nas pesquisas que envolvem a análise do comportamento é o uso do experimento, até o momento pouco utilizado nas pesquisas em contabilidade, sobretudo, a financeira.

Os experimentos buscam testar como, e por que, os fenômenos que ocorrem em contabilidade financeira podem estar baseados em teorias psicológicas, econômicas e processos institucionais (LIBBY; BLOOMFIELD; NELSON, 2002). Isto é, eles não só reportam a capacidade preditiva, mas complementam o entendimento de modelos econômicos e psicológicos e podem ser úteis à revisão de teorias que proporcionem melhor previsão do comportamento das pessoas nas organizações (SPINKLE, 2003).

$\mathrm{Na}$ pesquisa experimental, o pesquisador tem a liberdade de criar o ambiente adequado à sua investigação, pela manipulação das variáveis independentes e o controle de outras variáveis que possam influenciar o ambiente, mensurando, dessa forma, os processos e estados mentais que induzem o resultado final (LIBBY; BLOOMFIELD; NELSON, 2002).

$\mathrm{O}$ experimento tem a virtude de ir além da precisão no reporte das inter-relações entre as variáveis em estudo; ele também proporciona a investigação dos processos que ocorrem concomitantemente a essas relações (SPINKLE, 2003), proporcionando um melhor entendimento de aspectos subjacentes, como o comportamento do indivíduo em estudo. 
O comportamento nas tomadas de decisões econômico-financeiras tem sido motivo de diversos estudos, principalmente na área de finanças. Uma das razões para estes estudos está na premissa de racionalidade dos agentes econômicos (indivíduos ou empresas), que dá sustentação à maior parte da teoria econômica e financeira. Por essa premissa, os agentes são cem por centro racionais, usando todo o conjunto de informações disponíveis da melhor maneira possível. Entretanto, os comportamentos e decisões tomadas não evidenciam a existência de total racionalidade. O que se verifica, na realidade, é uma racionalidade limitada (MOSCA, 2009). Portanto, os tomadores de decisão são limitados em uma série de questões, inclusive sofrem pela limitação de informações e suas decisões são baseadas em seus insights e preferências (LIBBY; BLOOMFIELD; NELSON, 2002).

Como exemplo de aplicação do experimento, pode-se buscar conhecer que comportamento o profissional contabilista adota diante de decisões que envolvam o reconhecimento, registro e reporte de um fato econômico-financeiro. Tal comportamento deve ser mensurado e controlado num ambiente de pesquisa experimental, onde o experimentalista poderá manipular uma ou mais variáveis independentes a fim de analisar a validade de hipóteses pré-concebidas. Esse ambiente, elaborado de modo proposital para fins de pesquisa, pode funcionar como chamariz (ARIELY, 2008), com o objetivo de induzir o participante da pesquisa a agir de acordo com um padrão esperado; e as variáveis independentes serem utilizadas como variáveis de controle, com o objetivo de identificar diferentes padrões de comportamento de acordo com o cenário proposto.

Uma das análises que podem ser realizadas diz respeito ao grau de conservadorismo do participante da pesquisa. Nesta pesquisa, considerar-se-á conservador o profissional que procurar pautar suas decisões atribuindo maiores valores para passivos e despesas e menores valores para ativos e receitas, nos casos em que sejam possíveis mais de um tratamento contábil - conceito este alinhado ao que Watts (2003, p. 207) menciona: "conservadorismo é definido como a diferença da verificabilidade exigida para o reconhecimento dos lucros versus perdas [...] sua forma extrema de conservadorismo é como o tradicional ditado: não antecipar os lucros, mas antecipar todas as perdas".

\section{PROCEDER METODOLÓGICO}

A partir da manipulação proposital de variáveis, um experimento busca criar um ambiente favorável à geração de dados para a sua pesquisa. Essa manipulação é realizada nas variáveis independentes usando o princípio da aleatoriedade, permitindo ao pesquisador controlar o ambiente de pesquisa e isolar os efeitos das variáveis que seriam confundidas no ambiente natural (SPINKLE, 2003).

A vantagem do método experimental reside na sua capacidade de isolar fatores e permitir conclusões acerca do comportamento de certos fenômenos (LIBBY; BLOOMFIELD; NELSON, 2002). Na pesquisa ora realizada esses fatores estão representados, inicialmente de modo instrumental, pelo chamariz.

A pesquisa de campo foi estruturada em dois questionários, aplicados a 343 estudantes de graduação, de final de curso (sexto a oitavo semestres), e pós-graduação em Ciências Contábeis no segundo semestre de 2008. Aos respondentes foram solicitadas informações sobre seu perfil (idade, gênero e tempo de experiência na área de contabilidade), consideradas na análise como variáveis independentes.

Foram construídos dois tipos de questionários. O primeiro foi aplicado para 152 estudantes (Grupo 1 ou Sem Chamariz, que será explicado mais adiante) e o segundo para 191 (Grupo 2 ou Com Chamariz), totalizando 343 respondentes. As perguntas de ambos os questionários são idênticas, com alterações na parte introdutória (ambiente da pesquisa) e na forma de aplicação dos questionários. O Quadro 1 apresenta as diferenças na parte introdutória do questionário para os dois grupos (as partes semelhantes estão em itálico). É 
possível observar que para o Grupo 2 (Com Chamariz) foi enfatizada a necessidade de o resultado contábil ser favorável à expansão dos negócios e à remuneração.

\begin{tabular}{|c|c|}
\hline Grupo 1 - Sem Chamariz & Grupo 2 - Com Chamariz \\
\hline $\begin{array}{l}\text { Você está participando do } \\
\text { processo seletivo para a } \\
\text { vaga de contador-chefe } \\
\text { da empresa Bambolê S/A, } \\
\text { que deseja obter o maior } \\
\text { nível de conhecimento } \\
\text { acerca das decisões que } \\
\text { você poderá vir a tomar } \\
\text { dentro da empresa. Desde } \\
\text { já a empresa sinaliza que } \\
\text { você terá total liberdade } \\
\text { para tomar tais decisões, } \\
\text { cujas informações } \\
\text { financeiras, dentro de um } \\
\text { conceito de justiça e } \\
\text { verdade, serão } \\
\text { evidenciadas naos } \\
\text { acionistas que não } \\
\text { participam da gestão. }\end{array}$ & $\begin{array}{l}\text { Você está participando do processo seletivo para a vaga de contador-chefe da } \\
\text { empresa Bambolê S/A, que deseja obter o maior nível de conhecimento acerca } \\
\text { das decisões que você poderá vir a tomar dentro da empresa. Desde já a } \\
\text { empresa sinaliza que você terá total liberdade para tomar tais decisões. } \\
\text { Entretanto, a alta direção da empresa busca disseminar sua filosofia: foco em } \\
\text { resultados e a defesa de seus interesses, e os gestores que estão alinhados com } \\
\text { esta visão, são melhor avaliados para fins de ascensão profissional. } \\
\text { Para } 2008 \text {, a meta de resultado econômico-financeiro foi ousada e, portanto, está } \\
\text { sendo monitorada bem de perto pela diretoria, pois há probabilidade de que ela } \\
\text { venha a ser atingida, porém, sem qualquer folga. Essa meta foi proposta dentro } \\
\text { do plano de expansão dos negócios da empresa, que pretende captar recursos no } \\
\text { mercado por meio da emissão de debêntures em } 2009 \text {, para a concretização de } \\
\text { tal plano. } \\
\text { Com o recurso das debêntures, a empresa pretende abrir mais } 25 \text { filiais, e gerar } \\
\text { aproximadamente } 2.500 \text { novos empregos diretos, sem falar dos empregos } \\
\text { indiretos. Para tanto, terá de disponibilizar suas demonstrações contábeis após o } \\
\text { fechamento de } 2008 \text {, para constar no prospecto a ser disponibilizado à análise } \\
\text { dos potenciais debenturistas no mercado. Neste prospecto constarão as } \\
\text { demonstrações contábeis dos últimos cinco anos, inclusive o resultado de } 2008 \\
\text { que, caso se apresente abaixo da média dos anos anteriores, poderá colocar por } \\
\text { água abaixo um planejamento de } 10 \text { anos, devido ao deságio que as debêntures } \\
\text { sofreriam na sua emissão. } \\
\text { Além disso, todos os empregados já sabem que a bonificação anual depende dos } \\
\text { ajustes contábeis que estão sendo promovidos pelo contador-chefe. O benefício } \\
\text { por empregado equivale, em média, a quatro remunerações mensais se a } \\
\text { empresa atingir as metas. Conforme o estatuto da companhia, caso as metas não } \\
\text { sejam atingidas na íntegra, não será devido o pagamento do benefício. O registro } \\
\text { de qualquer despesa resultaria, portanto, na perda do benefício pelos } \\
\text { empregados neste exercício social. }\end{array}$ \\
\hline
\end{tabular}

Quadro 1 - Parte introdutória do questionário

Fonte: dados da pesquisa.

Para a formulação do referido questionário, buscou-se como base os assuntos tratados pela Deliberação CVM n 489/2005, que dispõe sobre as provisões, passivos, contingências passivas e contingências ativas. Além dos assuntos relacionados à contabilidade financeira, buscou-se formular as questões no sentido de não haver uma resposta considerada correta e outra considerada errada (DUXBURY; KEASEY; ZHANG; CHOW, 2005), haja vista que elas estão relacionadas a juízo de valor do respondente (CUCCIA, HACKENBRACK e NELSON, 1995; NELSON e KINNEY JR, 1997).

Para o Grupo 2, além da diferença na introdução de cada questionário, antes da aplicação do questionário para o Grupo 2, foram reproduzidos três vídeos (chamariz) trazendo reportagens veiculadas no Jornal Hoje (plano de recompensa a empregados - participação nos lucros e resultados), no Jornal das Dez da Globo News (depoimento da então ministra Marta Suplicy) e Jornal da Globo (comentário crítico de Arnaldo Jabor). Estes vídeos foram exibidos com a finalidade de induzir o respondente a agir de maneira mais agressiva, tendendo a realizar o gerenciamento de resultado em favor da empresa. Logo após a apresentação dos três vídeos, os respondentes receberam o questionário. Vale ressaltar que tanto os vídeos como as informações sobre as políticas tiveram por fim causar o efeito chamariz (ARIELY, 2008). Ademais, os vídeos compreendem um instrumento de varredura.

$\mathrm{O}$ restante do questionário é idêntico para ambos os grupos, apresentando quatro cenários para que o respondente escolhesse uma alternativa conforme a escala Likert $(1=$ 
discorda totalmente; 2 = discorda em parte; 3 = não concorda nem discorda; 4 = concorda em parte; 5 = concorda totalmente) e, por fim, numa última questão é solicitado o grau de segurança nas respostas. Por este motivo, a análise foi realizada para cada um dos cenários.

No que concerne à seleção dos participantes, estudos experimentais que visam testar previsões de tomadas de decisões podem justificar a escolha de estudantes, desde que estes já tenham se apropriado de conhecimentos suficientes acerca do fenômeno contábil tratado na pesquisa (LIYANARACHCHI, 2007). Dado que o experimento busca mensurar as atitudes de cada participante, no sentido de traduzir sua percepção acerca da tomada de decisão sobre um fato relacionado à contabilidade financeira (BEATTIE; JONES, 2002), e considerando o conhecimento necessário ao julgamento adequado das proposições do questionário, a pesquisa foi aplicada aos alunos das disciplinas intermediárias do curso de graduação, e acredita-se que a seleção da amostra é adequada ao estudo.

Em face do objetivo da pesquisa, a aplicação do experimento com estudantes é especialmente útil dada a possibilidade de criar-se um ambiente propício à identificação da influência do chamariz (sobretudo a aplicação dos vídeos) em grupos, como é o caso da amostra selecionada para este estudo.

Outro aspecto que pode ser destacado é que a substituição de profissionais por estudantes evita o uso de profissionais onde estes não são indispensáveis ao alcance das metas da pesquisa. Além do aumento de tempo e despesas para o pesquisador, o uso inapropriado de profissionais pode ter efeito negativo, pois eles podem tornar mais difícil o acesso a outros pesquisadores (LIBBY; BLOOMFIELD; NELSON, 2002).

Para o tratamento dos dados utilizaram-se diferentes técnicas estatísticas, conforme o conjunto de dados disponíveis. Inicialmente, a estatística descritiva, em particular mediana e moda, medidas de tendência central mais apropriadas para a escala Likert. O teste do quiquadrado foi usado para comparar as frequiências esperadas com as freqüências observadas. Para testar o índice de conservadorismo também foi utilizada a regressão linear múltipla.

Entre outras limitações que também devem ser consideradas, está o fato de que o estudo: a) não teve condições de capturar os efeitos decorrentes do período histórico em que os questionários foram aplicados - início da crise financeira ocorrida em setembro de 2008; b) possui uma inerente dificuldade em identificar e quantificar todas as variáveis simultaneamente em um único experimento; c) não poderá ter suas considerações generalizadas, tampouco, atribuídas aos profissionais contábeis em um momento de tomada de decisão em um ambiente cotidiano (LIBBY; BLOOMFIELD; NELSON, 2002).

\section{ANÁLISE DOS RESULTADOS}

\subsection{Resultados dos cenários}

$\mathrm{Na}$ análise dos resultados foram considerados primeiramente, em cada etapa da análise, um dos cenários apresentados aos respondentes da pesquisa.

Cenário 1 - A Bambolê S/A é controladora da Desastrada S/A. Em dezembro de 2008, a Desastrada S/A tem ciência de um relevante prejuízo relacionado a determinado projeto, mas ainda não reconhecido nas suas demonstrações contábeis. A Bambolê S/A, como controladora, é co-participante e deverá arcar com o prejuízo. Para fechar o balanço de 2008, você recomendaria à Desastrada S/A reconhecer a perda e detalhá-la em notas explicativas. Na Bambolê S/A, reconheceria uma provisão para perda e divulgaria o fato em notas explicativas.

Apesar do termo mais correto ser "co-responsável" ou "solidário", os autores decidiram manter o termo "co-participante", utilizado no questionário. Acredita-se que este problema não influenciou o resultado.

Este cenário mostra uma situação onde o reconhecimento do prejuízo na Desastrada afetaria o resultado da empresa Bambolê. Em razão da introdução para o grupo com chamariz, esperava-se uma reação de maior discordância deste grupo, em razão do mesmo induzir a 
maior agressividade. Ou seja, o chamariz afetaria a decisão. A Tabela 1 apresenta os resultados obtidos, em que a mediana e a moda são iguais para os dois grupos. Entretanto, é possível observar que o grau de concordância para o grupo Sem Chamariz, que é representado pelas respostas "concordo totalmente" e "concordo em parte", é maior (87\% versus $67 \%$ ), o que pode revelar uma influência, mesmo que reduzida, do chamariz na resposta.

\begin{tabular}{lccc}
\hline Discriminação & Sem Chamariz & Com Chamariz & Total \\
\hline Mediana & 4 & 4 & 4 \\
Moda & 5 & 5 & 5 \\
\% Concordância & $87 \%$ & $67 \%$ & $76 \%$ \\
\% Indiferença & $4 \%$ & $15 \%$ & $10 \%$ \\
\% Discordância & $9 \%$ & $18 \%$ & $14 \%$ \\
Discordo totalmente & 5 & 11 & 16 \\
Discordo em parte & 9 & 24 & 33 \\
Não concorda nem discorda & 6 & 29 & 35 \\
Concorda em parte & 59 & 61 & 120 \\
Concordo totalmente & $\underline{73}$ & $\underline{66}$ & $\underline{139}$ \\
Total & 152 & 191 & 343 \\
\hline
\end{tabular}

Tabela 1 - Resultado do Cenário 1

Fonte: dados da pesquisa.

Com efeito, o resultado do qui-quadrado $(=20,398 ; 0,000$ de significância) mostra que o chamariz afetou os resultados obtidos. Neste caso, o chamariz influenciou uma maior discordância nas respostas, ou seja, a escolher alternativas menos conservadoras e contrárias à boa técnica contábil. Em outras palavras, o fator externo (chamariz) exerceu influência sobre as escolhas contábeis.

Cenário 2 - No ano de 2008, devido à competitividade no setor de eletrodomésticos, a Bambolê S/A decidiu utilizar material de qualidade inferior em seus produtos, procurando reduzir custos e melhorar seu preço final. $\mathrm{O}$ departamento técnico já alertou que isso trará aumento de gastos com manutenções no período da garantia, o que repercutirá na conta provisão de garantia de produtos. Como contador-chefe você não faria qualquer ajuste na conta de provisão, nem mencionaria o fato em notas explicativas, pois isso poderia ter um impacto muito negativo para a imagem da empresa no mercado.

Este cenário mostra a situação em que uma empresa deve ou não aumentar a provisão para garantia de produtos, com reflexo no resultado. Neste cenário o chamariz não fez diferença, como pode ser observado pela mesma mediana e mesma moda na Tabela 2. Os percentuais de concordância, indiferença e discordância obtidos são próximos.

\begin{tabular}{lccc}
\hline Discriminação & Sem Chamariz & Com Chamariz & Total \\
\hline Mediana & 4 & 4 & 4 \\
Moda & 5 & 5 & 5 \\
\% Concordância & $72 \%$ & $68 \%$ & $70 \%$ \\
\% Indiferença & $7 \%$ & $8 \%$ & $8 \%$ \\
\% Discordância & $21 \%$ & $24 \%$ & $18 \%$ \\
Discordo totalmente & 10 & 15 & 10 \\
Discordo em parte & 22 & 30 & 52 \\
Não concorda nem discorda & 11 & 16 & 27 \\
Concorda em parte & 47 & 47 & 94 \\
Concordo totalmente & $\underline{62}$ & $\underline{83}$ & $\underline{145}$ \\
Total & 152 & 191 & 343 \\
\hline
\end{tabular}

Tabela 2 - Resultado do Cenário 2

Fonte: dados da pesquisa.

O resultado do qui-quadrado $(=1,787 ; 0,775$ de significância) confirma que o chamariz não foi relevante para as respostas. 
Cenário 3 - A Bambolê S/A possui uma causa trabalhista de um ex-presidente. Conforme a Deliberação CVM n ${ }^{\circ}$ 489/05, se a probabilidade de perda da causa for "provável", registra-se a provisão; se for "possível", apenas relata-se em notas explicativas; e, se "remota", não precisa de divulgação. Para o advogado Dr. Nilton ela é "possível”, mas acha que não deveria divulgar nada para preservar a imagem da empresa no mercado de ações. Os diretores estão confiantes, pois uma provisão mudaria o resultado da empresa de lucro para prejuízo. Contudo, você sabe que o Dr. Nilton não teve sucesso em causas similares em outras ocasiões, e colocou a empresa em situação difícil perante aos acionistas. Com base em argumentos técnicos, você reconhece a causa como "provável", e orienta seu registro e divulgação.

Neste caso a presença do chamariz não afetou de forma relevante o resultado. Conforme pode ser notado na Tabela 3, a mediana e a moda são iguais e o percentual de concordância é razoavelmente próximo.

\begin{tabular}{lccc}
\hline Discriminação & Sem Chamariz & Com Chamariz & Total \\
\hline Mediana & 4 & 4 & 4 \\
Moda & 5 & 5 & 5 \\
\% Concordância & $68 \%$ & $61 \%$ & $64 \%$ \\
\% Indiferença & $10 \%$ & $10 \%$ & $10 \%$ \\
\% Discordância & $22 \%$ & $29 \%$ & $26 \%$ \\
Discordo totalmente & 9 & 23 & 32 \\
Discordo em parte & 24 & 33 & 57 \\
Não concorda nem discorda & 16 & 19 & 35 \\
Concorda em parte & 45 & 51 & 96 \\
Concordo totalmente & $\underline{58}$ & $\underline{65}$ & $\underline{123}$ \\
Total & 152 & 191 & 343 \\
\hline
\end{tabular}

Tabela 3 - Resultado do Cenário 3

Fonte: dados da pesquisa.

O resultado do teste do qui-quadrado $(=4,196 ; 0,380$ de significância) permite afirmar que o chamariz não afetou a decisão de reconhecer a provisão, fazendo o registro considerado mais adequado.

Cenário 4 - Com as alterações promovidas pela Lei $\mathrm{n}^{\circ}$ 11.638/2007, Lei das S/A, o Ativo Diferido comporta somente gastos pré-operacionais e de reestruturação que tenham repercussão superior a 1 ano. Em 2008, a empresa Bambolê S/A implantou um novo software e treinou seus funcionários. Você foi contra, pois o software não atenderia às necessidades da empresa e não teve sucesso em outras companhias. Os gastos seriam lançados como despesas, ficando o resultado aquém do proposto como meta para o período. Como a Deliberação CVM $\mathrm{n}^{\circ}$ 489/2005 não veda expressamente tal lançamento no Ativo Diferido, você aproveitou essa "brecha" na legislação e registrou os gastos no ativo diferido, até porque seus efeitos se caracterizam como reestruturação organizacional.

O registro como diferido tende a aumentar o resultado, sendo uma política contábil mais agressiva. Neste cenário, a presença do chamariz não influenciou o resultado uma vez que a mediana e a moda são iguais, ou seja, os respondentes não concordam com o registro como diferido, conforme consta na Tabela 4.

\begin{tabular}{lccc}
\hline Discriminação & Sem Chamariz & Com Chamariz & Total \\
\hline Mediana & 2 & 2 & 2 \\
Moda & 2 & 2 & 2 \\
\% Concordância & $28 \%$ & $31 \%$ & $30 \%$ \\
\% Indiferença & $16 \%$ & $17 \%$ & $16 \%$ \\
\% Discordância & $56 \%$ & $52 \%$ & $53 \%$ \\
Discordo totalmente & 24 & 33 & 57 \\
Discordo em parte & 60 & 66 & 126 \\
Não concorda nem discorda & 24 & 32 & 56 \\
Concorda em parte & 26 & 37 & 63 \\
Concordo totalmente & $\underline{17}$ & $\underline{22}$ & $\underline{39}$ \\
Total & 151 & 190 & 341 \\
\hline
\end{tabular}

Tabela 4 - Resultado do Cenário 4

Fonte: dados da pesquisa. 
Os resultados do teste do qui-quadrado confirmam que o chamariz não influenciou os resultados: 0,963, significante a 0,915 .

Em seguida buscou-se verificar se o gênero, a idade e a experiência afetaram as respostas apresentadas nos quatro cenários. As variáveis idade e experiência foram transformadas em binárias, usando como parâmetro a mediana. Deste modo, respondentes com idade acima de 24 anos, inclusive, foram classificados como "seniores" e aqueles com idade menor que 24 anos foram classificados como "juniores". Já aqueles sem experiência de trabalho na área contábil ou com até um ano de experiência compuseram o grupo dos inexperientes. Os respondentes com mais de um ano de experiência foram considerados como "experientes" para fins da pesquisa.

Os resultados dos cenários, que na escala Likert apresenta cinco possíveis respostas, foram transformados em variáveis binárias, sendo zero a discordância e um a concordância. A indiferença não foi considerada, e esta decisão provavelmente não influenciou o resultado, já que foram poucas as respostas neste sentido (Tabelas 1 a 4). A principal razão desta transformação é de ordem prática: como o teste do qui-quadrado apresenta problemas quando o número de observações em cada cruzamento é menor que cinco, a transformação em variável binária elimina-os. Testes realizados, que não estão apresentados neste texto, mostraram que a transformação não afetou o resultado.

Cenário 5 - Quanto às decisões tomadas nos cenários apresentados na pesquisa, você está totalmente seguro1.

Esta questão teve como finalidade certificar-se do grau de certeza (ou de confiança) dos respondentes. Aqueles que responderam 4 ou 5 (concordo totalmente e concordo) foram classificados como "confiantes" da sua resposta; os que responderam 1 ou 2 (discordo totalmente e discordo) foram considerados como "dúvidas". Apesar de no questionário isto estar como um "cenário", foi tratado na pesquisa como uma variável independente.

Procurou-se verificar se as variáveis de controle (idade, gênero, experiência, certeza e escolaridade) influenciavam os resultados obtidos.

\begin{tabular}{llcccc}
\hline Variáveis de controle & Grupos & Cenário 1 & Cenário 2 & Cenário 3 & Cenário 4 \\
\hline Idade & Juniores & $\mathbf{4 , 0 9 6}(\mathbf{0 , 0 4 3})$ & $0,250(0,617)$ & $\mathbf{3 , 3 6 1}(\mathbf{0 , 0 6 7})$ & $0,011(0,918)$ \\
& Seniores & $\mathbf{4 , 0 6 7}(\mathbf{0 , 0 4 4})$ & $0,036(0,850)$ & $0,226(0,635)$ & $0,940(0,332)$ \\
Gênero & Feminino & $1,705(0,192)$ & $0,061(0,805)$ & $0,008(0,927)$ & $0,005(0,946)$ \\
& Masculino & $\mathbf{8 , 9 0 9}(\mathbf{0 , 0 0 3})$ & $0,411(0,522)$ & $\mathbf{4 , 0 8 0}(\mathbf{0 , 0 4 3})$ & $0,478(0,489)$ \\
Experiência & Inexperientes & $\mathbf{1 1 , 2 9 0}(\mathbf{0 , 0 0 1})$ & $\mathbf{4 , 1 6 3 ( 0 , 0 4 1 )}$ & $2,400(0,121)$ & $0,314(0,575)$ \\
& Experientes & $0,619(0,431)$ & $0,320(0,571)$ & $0,586(0,444)$ & $0,192(0,661)$ \\
Escolaridade & Graduandos & $\mathbf{8 , 8 5 6}(\mathbf{0 , 0 0 3 )}$ & $1,540(0,215)$ & $1,494(0,222)$ & $0,373(0,542)$ \\
& Pós-graduandos & $0,079(0,779)$ & $\mathbf{2 , 8 4 4}(\mathbf{0 , 0 9 2})$ & $1,767(0,184)$ & $0,159(0,690)$ \\
Certeza & Dúvidas & $0,383(0,536)$ & $\mathbf{3 , 0 2 0}(\mathbf{0 , 0 8 2})$ & $0,385(0,535)$ & $0,100(0,752)$ \\
& Confiantes & $\mathbf{1 4 , 1 5 8}(\mathbf{0 , 0 0 0 )}$ & $0,327(0,568)$ & $\mathbf{3 , 7 5 9}(\mathbf{0 , 0 5 3})$ & $0,184(0,668)$ \\
\hline Geral & & $\mathbf{2 0 , 3 9 8}(\mathbf{0 , 0 0 0})$ & $1,787(0,775)$ & $4,196(0,380)$ & $0,963(0,915)$ \\
\hline
\end{tabular}

Tabela 5 - Resultado dos cenários com variáveis de controle

Fonte: dados da pesquisa.

Observação: valores em negrito indicam resultados com significância menor que 10\%; valores em negrito e itálico correspondem aos resultados com significância menor que 5\%.

A Tabela 5 apresenta o resultado do teste qui-quadrado usando como cruzamento a presença ou não do chamariz, cada um dos cenários e as variáveis. Além do valor do teste, entre parênteses está a significância. Para fins de comparação também foi apresentado o resultado geral, no final da Tabela 5.

O cenário 1, onde o chamariz teve influência sobre as respostas, também foi afetado pela idade dos respondentes. É interessante notar que tanto os juniores quanto os seniores foram influenciados pelo chamariz. Mas outras variáveis de controle só foram influenciadas 
por parte dos respondentes (no caso, os homens, os inexperientes, os confiantes e os graduandos, que foram influenciados pelo chamariz).

O cenário 2 apresenta um resultado mais interessante. Conforme comentado anteriormente, neste cenário em que se questionava a contabilização da provisão para garantia, o chamariz não influenciou as respostas de uma maneira geral. Entretanto, quando se analisam os grupos de respondentes, nota-se que os mais inexperientes, os que estavam fazendo pós-graduação e aqueles que tinham dúvidas sobre a resposta dada no questionário sofreram influência do chamariz.

O cenário 3, referente à provisão para causa trabalhista, o chamariz não provocou nenhum efeito sobre o resultado. No entanto, quando se analisam os diversos grupos de respondentes percebe-se que os homens, os confiantes e os mais jovens foram particularmente afetados pelo chamariz.

Finalmente, o cenário 4 apresentou reduzida influência do chamariz quando se usam as variáveis de controle. Uma possível razão para este fato talvez esteja no uso da palavra "brecha" no texto, entre aspas, que pode ter sido assimilado pelos respondentes como algo próximo à ilegalidade.

\section{2 Índice de conservadorismo}

Por meio de uma escala Likert (1 a 5) procurou-se mensurar o conservadorismo dos respondentes quanto à tomada de decisão diante dos cenários apresentados. Isto inclui o reflexo no resultado líquido da empresa, seja para aumentá-lo - menor conservadorismo, seja para diminuí-lo - maior conservadorismo (WATTS, 2003).

Foi utilizada uma escala de 1 a 5, variando entre discordo totalmente (1) e concordo totalmente (5). A utilização desta escala visa medir, com maior precisão, a opinião do respondente. Logo, quanto mais próximo de (1), maior será a probabilidade de o respondente agir em desacordo com o cenário proposto, e, quanto mais próximo de (5), maior a probabilidade de ele agir em conformidade com o cenário. As interpretações dos cenários propostos atenderiam as escalas apresentadas no Quadro 1.

\begin{tabular}{|l|c|c|c|c|c|}
\hline & $\begin{array}{c}\text { Discordo } \\
\text { Totalmente }\end{array}$ & Discordo & Indiferente & Concordo & $\begin{array}{c}\text { Concordo } \\
\text { Totalmente }\end{array}$ \\
\hline Cenário 1 & $+\mathrm{A}$ & $\mathrm{A}$ & $\mathrm{I}$ & $\mathrm{C}$ & $+\mathrm{C}$ \\
\hline Cenário 2 & $+\mathrm{C}$ & $\mathrm{C}$ & $\mathrm{I}$ & $\mathrm{A}$ & $+\mathrm{A}$ \\
\hline Cenário 3 & $+\mathrm{A}$ & $\mathrm{A}$ & $\mathrm{I}$ & $\mathrm{C}$ & $+\mathrm{C}$ \\
\hline Cenário 4 & $+\mathrm{C}$ & $\mathrm{C}$ & $\mathrm{I}$ & $\mathrm{A}$ & $+\mathrm{A}$ \\
\hline
\end{tabular}

Quadro 1 - Escala utilizada no questionário de pesquisa

Fonte: dados da pesquisa.

Legenda: +A (mais agressivo); A (agressivo); I (indiferente); C (conservador); +C (mais conservador).

Assim, se o respondente concordou no Cenário $1 \mathrm{com}$ a proposta de ação, ele adotou uma atitude conservadora, já que há concordância significava em reconhecer a provisão para perda. No Cenário 2, a atitude mais conservadora é a discordância da ação proposta, qual seja, não fazer ajuste na provisão. No Cenário 3, a atitude conservadora é o registro da provisão. Finalmente, no Cenário 4, a atitude conservadora é discordar da solução da empresa, que é registrar os gastos no diferido.

Conforme a resposta de cada participante, atribuiu-se 5 pontos para respostas mais conservadoras (+C); 4 pontos para conservadoras $(\mathrm{C}) ; 3$ pontos para indiferentes (I); 2 pontos para agressivas (A); e 1 ponto para mais agressivas (+A). $\mathrm{O}$ índice de conservadorismo de cada participante corresponde à soma destes pontos. 
Assim, se um respondente marcou nos quatro cenários do seu questionário que concorda totalmente, que é indiferente, que concorda e que discorda totalmente, teria a conversão na escala de conservadorismo, conforme Quadro 2.

\begin{tabular}{|c|l|c|c|}
\hline Cenário & \multicolumn{1}{|c|}{ Resposta } & Escala (Quadro 1) & Pontos \\
\hline 1 & Concorda Totalmente & $+\mathrm{C}$ & 5 \\
\hline 2 & Indiferente & $\mathrm{I}$ & 3 \\
\hline 3 & Concorda & $\mathrm{C}$ & 4 \\
\hline 4 & Discorda Totalmente & $+\mathrm{C}$ & 5 \\
\hline Total & \multicolumn{2}{|c|}{} \\
\hline
\end{tabular}

Quadro 2 - Exemplo do índice de conservadorismo

Fonte: dados da pesquisa.

Através do índice de conservadorismo, será possível determinar a influência das variáveis de controle e do chamariz na resposta das pessoas. Para isto, calculou-se a regressão linear múltipla entre o conservadorismo e estas variáveis. Também foram usados outros modelos, mas a qualidade estatística dos resultados não é substancialmente diferente do modelo de regressão linear múltipla. Optou-se por apresentar somente o resultado deste modelo pelo fato de ser muito usado na prática (HAIR et al., 2005) e permitir uma análise mais profunda dos dados.

$$
\begin{aligned}
& \text { CONSERV }=a+b_{1} I D A D E+b_{2} \text { EXPERIENNCIA }+b_{3} G E N E R O+b_{4} D C E R T E Z A+ \\
& b_{5} \text { ESCOLARIDADE }+b_{6} C H A M A R I Z
\end{aligned}
$$

Usando o método Stepwise encontraram-se os seguintes resultados:

$$
\begin{aligned}
& \text { CONSERV }=12,838+0,945 \text { DCERTEZA }-0,850 \text { CHAMARIZ } \quad R=0,209 \quad D W=1,917 \\
& 0,404 \quad 0,407 \quad 0,303 \quad F_{c}=6,547
\end{aligned}
$$

O método Stepwise considera somente as variáveis que são significativas, descartando aquelas que não são relevantes estatisticamente. A regressão mostra que o nível de conservadorismo depende do grau de certeza do respondente - pessoas com maior certeza nos cenários são mais conservadoras; pessoas que têm dúvida na sua própria resposta tendem a ser menos conservadoras - e do efeito chamariz, que contribuiu, negativamente, com o nível de conservadorismo.

Também foi realizada uma regressão somente com os valores extremos do índice de conservadorismo, retirando os questionários próximos à mediana (valores de 12, 13 e 14 pontos). Este cálculo é no sentido de retirar os respondentes que não eram nem agressivos nem conservadores dos cálculos. O número de observações usado foi de 199, em lugar dos 343 dados da regressão original e o resultado foi o seguinte:

$$
\begin{aligned}
& \text { CONSERV }=12,912+1,388 \text { DCERTEZA }-1,374 \text { CHAMARIZ } \quad R=0,266 \quad D W=1,852 \\
& 0,641 \quad 0,637 \quad 0,508 \quad F_{c}=6,281
\end{aligned}
$$

Ou seja, a regressão com participantes com valores mais extremos apresentou um resultado muito próximo ao encontrado com a regressão.

Finalmente, os valores do índice de conservadorismo menores ou iguais a 11 foram considerados agressivos e os valores maiores ou iguais a 15 foram classificados como conservadores. (Os valores acima de 11 e menor que 15 não foram considerados). Em outras palavras, transformou-se uma variável continua numa variável binária (DCONSERV). Com 
esta nova variável, calculou-se o valor do qui-quadrado em relação às cinco variáveis binárias da Tabela 5, apresentadas anteriormente, além do chamariz.

Dos 87 respondentes classificados como menos conservadores, 54 responderam o questionário com chamariz e $33 \mathrm{sem}$; já aqueles que foram mais conservadores, 51 responderam com chamariz e 54 sem chamariz. Apesar da postura mais agressiva dos participantes da pesquisa que tiveram o chamariz, o resultado do teste do qui-quadrado $(=2,189 ; 0,139$ de significância) não permite afirmar, com certeza, que o chamariz tornou as pessoas mais agressivas nas escolhas contábeis, de maneira geral (Tabela 6). Também foi realizado o teste usando idade, gênero, experiência, escolaridade e certeza como variáveis de controle. Apesar de em geral a amostra não apresentar influência do chamariz na classificação dos dois grupos (105 mais conservadores versus 87 menos conservadores), em dois subgrupos o chamariz foi relevante: entre os mais seniores e nos homens.

\begin{tabular}{llc}
\hline Variáveis de controle & Grupos & Conservadorismo \\
\hline Idade & Juniores & $0,004(0,950)$ \\
Gênero & Seniores & $\mathbf{4 , 0 3 0}(\mathbf{0 , 0 4 5})$ \\
& Feminino & $0,000(1,000)$ \\
Experiência & Masculino & $\mathbf{4 , 0 4 9}(\mathbf{0 , 0 4 4 )}$ \\
& Inexperientes & $1,398(0,237)$ \\
Escolaridade & Experientes & $0,896(0,344)$ \\
& Graduandos & $0,186(0,666)$ \\
Certeza & Pós-graduandos & $1,0703(0,300)$ \\
& Dúvidas & $0,050(0,823)$ \\
Geral & Confiantes & $1,980(0,159)$ \\
\hline
\end{tabular}

Tabela 6 - Conservadorismo, chamariz e variáveis de controle

Fonte: dados da pesquisa.

Observação: valores em negrito e itálico correspondem aos resultados com significância menor que $5 \%$.

\section{CONSIDERAÇÕES FINAIS}

Em situações ideais, o contador deveria tomar decisões tendo como base seu conhecimento da ciência, sem deixar-se influenciar por questões do ambiente. Esta pesquisa procurou verificar se isto ocorre na situação relacionada com as provisões de contingências passivas onde o conservadorismo encontra-se presente. Os resultados apresentados mostraram que a presença do chamariz pode afetar as decisões contábeis. Além disto, o estudo mostrou que a influência pode variar conforme o perfil do indivíduo.

Estas conclusões naturalmente devem ser consideradas dentro das limitações e limites da metodologia e da amostra usada pelos autores. Entretanto, as conclusões do estudo trazem importantes implicações, no sentido que alerta para a necessidade de considerar os fatores externos nos processos de escolhas contábeis. Futuras replicações do trabalho, com variações na amostra e no tema contábil podem enriquecer as conclusões obtidas no texto, confirmandoas ou permitindo um debate sobre o assunto. Entretanto, baseado nos resultados obtidos no estudo, acredita-se ser possível afirmar que fatores externos - no caso um chamariz influenciam o processo decisório do contador.

Provavelmente, parte do resultado pode ter sido influenciada pela forma de aplicação. Uma vez que os questionários foram aplicados em sala de aula, aspectos relativos à influência dos grupos sobre o comportamento das pessoas podem ter afetado os resultados, reduzindo o efeito chamariz. Um outro fator diz respeito à própria distribuição amostral, uma vez que há uma predominância no grupo de inexperientes e mais jovens.

Em face das observações do parágrafo anterior, os autores acreditam que os resultados desta pesquisa não podem ser extrapolados para toda e qualquer população, e sugerem a 
realização de novos experimentos com amostras que apresentem uma distribuição mais próxima da normal e em ambiente distinto do utilizado neste trabalho.

\section{REFERÊNCIAS}

ABOODY, David; LEV, Baruch. Information asymmetry, R\&D, and insider gains. The Journal of Finance, v. 55, n. 6, p.2747-2766, Dec., 2000. http://dx.doi.org/10.1111/0022$\underline{1082.00305}$

AKERLOF, George A. The market for "Lemons": quality uncertainty and the market mechanism. The Quarterly Journal of Economics, v. 84, n. 3, p. 488-500, Aug., 1970. http://dx.doi.org/10.2307/1879431

ALVES, Jorge Luiz; BORBA, José Alonso. A relevância da informação contábil ambiental para a tomada de decisão de investimento: um estudo experimental. In: Congresso USP de Controladoria e Contabilidade, 9., 2009, São Paulo. Anais ... São Paulo: FEA/USP, 2009.

ARIELY, Dan. Previsivelmente irracional: como as situações do dia-a-dia influenciam nossas decisões. Rio de Janeiro: Elsevier, 2008.

BEATTIE, Vivien; JONES, Michael John. Measurement distortion of grapas in corporate reports: an experimental study. Accounting, Auditing \& Accountability Journal, v. 15, n. 4, p. 546-564, 2002. http://dx.doi.org/10.1108/09513570210440595

CARDOSO, Ricardo Lopes; AQUINO, André Carlos Busanelli de. An experimental investigation of vagueness on the left side of balance sheet. In: IAAER-ANPCONT International Accounting Congress, 3., 2009, São Paulo. Anais ... São Paulo: FEA/USP, 2009.

COMISSÃO DE VALORES MOBILIÁRIOS (CVM). Deliberação CVM n 489, de 03 de outubro de 2005. Disponível em: 〈http://www.cvm.gov.br〉. Acesso em: em 01 set 2008.

CUCCIA, Andrew D.; HACKENBRACK, Karl; NELSON, Mark W. The ability of professional standards to mitigate aggressive reporting. The Accounting Review, v. 70, p. 227-248, Apr., 1995.

DUXBURY, Darren; KEASEY, Kevin; ZHANG, Hao; CHOW, Loong. Mental accounting and decision making: evidence under reverse conditions where money is spent for time saved. Journal of Economic Psychology, v. 26, p. 567-580, 2005. http://dx.doi.org/10.1016/i.joep.2004.11.001

GÂRLEANU, Nicolae; PEDERSEN, Lasse Heje. Adverse selection and the required return. The Review of Financial Studies, v. 17, n.3, Aug., 2004. http://dx.doi.org/10.1093/rfs/hhg032

GUALA, Francesco. Experimental economics, history of. The new palgrave dictionary of economics (Online). 2. ed. Eds. Steven N. Durlauf and Lawrence E. Blume. Palgrave Macmillan, 2008. Disponível em: <http://www.dictionaryofeconomics.com/article?id=pde2008_E000289>. Acesso em: 24 April 2009.

JENSEN, M. C. A theory of the firm: governance, residual claims, and organizational forms. Cambridge: Harvard University Press, 2003.

LIBBY, Robert; BLOOMFIELD, Robert; NELSON, Mark W. Experimental research in financial accounting. Accounting, Organizations and Society, v. 27, p. 775-810, 2002. http://dx.doi.org/10.1016/S0361-3682(01)00011-3 
LIYANARACHCHI, Gregory A. Feasibility of using student subjects in accounting experiments: a review. Pacific Accounting Review, v. 19, n. 1, p.47-67, 2007. http://dx.doi.org/10.1108/01140580710754647

MACHO-STADLER, Inés; PÉREZ-CASTRILLO, J. David. An introduction to the economics of information. Oxford: Oxoford, 2001.

MOSCA, Aquiles. Finanças comportamentais. Rio de Janeiro: Elsevier, 2009.

NELSON, Mark W.; KINNEY JR, William R. The effect of ambiguity on loss contingency reporting judgments. The Accounting Review, v. 72, p. 257-274, Apr, 1997.

PAULY, Mark V. Overinsurance and public provisiono of insurance: the roles of moral hazard and adverse selection. The Quarterly Journal of Economics, v. 88, n. 1, p. 44-62, Fev, 1974. http://dx.doi.org/10.2307/1881793

PUELZ, Robert; SNOW, Arthur. Evidence on adverse selection: equilibrium signaling and cross-subsidization in the insurance market. The Journal of Political Economy, v. 102, n. 2, p. 236-257, Apr., 1994. http://dx.doi.org/10.1086/261930

SMITH, Vernon L. Experimental economics. The new palgrave dictionary of economics. 2.. ed. Eds. Steven N. Durlauf and Lawrence E. Blume. Palgrave Macmillan, 2008. Disponível em: <http://www.dictionaryofeconomics.com/article?id=pde2008_E000277>. Acesso em: 24 April 2009.

STIGLITZ, Joseph E.; WEISS, Andrew. Credit rationing in markets with imperfect information. The American Economic Review, v. 71, n. 3, p. 393-410, Jun., 1981.

SPENCE, Michael. Job market signaling. The Quarterly Journal of Economics, v. 87, n. 3, p. 355-374, Aug., 1973. http://dx.doi.org/10.2307/1882010

SPRINKLE, Geoffrey B. Perspectives on experimental research in managerial accounting. Accounting, Organizations and Society, v. 28, p. 287-318, 2003. http://dx.doi.org/10.1016/S0361-3682(01)00058-7

\footnotetext{
${ }^{\mathrm{i}}$ Os autores agradecem as contribuições dos pareceristas, que possibilitaram uma série de melhorias ao artigo. Naturalmente que os erros aqui cometidos são de exclusiva responsabilidade dos autores.
} 